\title{
DURABILITY OF FRP REINFORCEMENTS AND LONG-TERM PROPERTIES
}

\author{
Katarína GAJDOŠOVÁ1*, Róbert SONNENSCHEIN', Stanislav BLAHO', Simona KINČEKOVÁ', Ján PECKA'
}

\begin{abstract}
Although fiber-reinforced polymers (FRPs) have achieved increasing popularity in strengthening concrete structures and reinforcing new ones, there is to date insufficient knowledge about their long-term behavior. The long-term properties of FRPs specified in design codes lead to the low utilization capacity of these materials and are not supposed to be correct according to the actual behavior of structures reinforced with FRPs after 20 or 30 years of their use. Environmental impact reduction factors limit the mechanical properties of FRP composites in a range from 0.95 for CFRP to 0.5 for GFRP; the creep rupture factor is from 0.9 to 0.2 . The paper summarizes previous research and experimental studies on the long-term properties of FRP reinforcements and also their comparison with the actual structures in which this reinforcement has been used; it presents the first part of an experimental investigation with comparative calculations.
\end{abstract}

\section{Address}

1 Dept. of Concrete Structures and Bridges, Faculty of Civil Engineering, Slovak University of Technology in Bratislava, Bratislava, Slovakia

* Corresponding author: katarina.gajdosova@stuba.sk

\section{Key words}

- GFRP reinforcement,

- Long-term properties,

- Creep-rupture,

- Long-term reduction factors.

\section{INTRODUCTION}

Fiber-reinforced polymer (FRP) reinforcement has become widely used for strengthening structures with insufficient reliability levels and for reinforcing new structures in special conditions where traditional steel reinforcement is not suitable, e.g., in an environment with chloride ions, when non-conductivity is needed, or when the reinforcement in concrete should not affect magnetic fields.

The characteristics of FRP reinforcements are dependent on factors such as the fiber's volume, the type of fiber, the type of resin, the orientation of the fiber, the dimensional effects, and the quality control during manufacturing (ACI 440.1R-15, 2015). The resin acts as a matrix bonding the fibers together and transferring the load applied to the composite between each of the individual fibers. The resin also protects the fibers from abrasion and impact damage as well as severe environmental conditions (water, salts, alkalis) that affect the durability of FRP products (Benmokrane et al., 2015). The most commonly used fibers are carbon (forming Carbon Fiber-Reinforced Polymer =
CFRP), glass (forming GFRP), aramid (forming AFRP) and basalt (forming BFRP) fibers.

Glass fibers are the cheapest ones but are less durable due to their high chemical sensitivity to an alkali environment. Carbon fibers tend to show the best resistance. CFRP and AFRP reinforcements are also insensitive to chloride ions. Carbon and glass fibers do not absorb water; thanks to that property, they have better fatigue strength. The most discussed problem of non-metallic reinforcement is its behavior during elevated temperatures, which is the problem when using resin. The carbon fibers themselves are not sensitive to high temperatures, which is why CFRP shows the most favorable behavior. In addition, CFRPs are not affected by ultraviolet rays.

The durability of an FRP reinforcement is not only influenced by its component properties but also by the interface between the components. The transfer of shear and transverse forces at the interface between the reinforcement and concrete, which influences the bond, and between the individual fibers within the composite are the resin-dominated mechanisms. Fiber-dominated mechanisms control 
properties such as the longitudinal strength and stiffness of a FRP reinforcement (Ceroni et al., 2006).

\section{LONG-TERM PROPERTIES}

To date, there is not enough information about the long-term behavior of FRP reinforcements, because they have not been used for a long period of time and because structures with FRP reinforcement or strengthening systems have not yet reached their predicted service life.

Of the long-term properties of an FRP reinforcement, the most important are durability, creep rupture, and fatigue. The durability of an FRP reinforcement is affected by an alkali environment in concrete and the access of moisture. The creep rupture phenomenon appears after a period of time when the FRP is subjected to a constant load and suddenly fails. The creep rupture and fatigue strength both depend on the type of fiber in an FRP reinforcement.

According to various standards, the long-term properties of FRP reinforcement are calculated from the short-term properties by the introduction of reduction factors. Properties reduced according to these requirements are very low, and the use of an FRP reinforcement does not seem to be effective. It must be stated that reduction factors for long-term properties have not yet been measured experimentally; they have only been extrapolated over time from accelerated shortterm tests. Some field investigations ten years after the application of a FRP reinforcement contradict the results of accelerated tests.

\subsection{Durability}

Durability is an essential attribute of most building materials and components. The durability of an FRP reinforcement may be defined as the ability to resist weathering action and chemical attacks while maintaining its desired engineering properties. If durability is to be a criterion, it should be expressed in quantitative terms to help in deciding whether the criteria of durability performance are met.

The lack of design rules for the use of FRP for the reinforcing and strengthening of concrete structures is also related to the durability of the design. Thus, because experimental tests for durability take a long time, accelerated methods are usually used. To this date, no real-time test data exist for the conversion of accelerated test results. The specification of the durability characteristics of an FRP reinforcement is also complicated by its structure because it depends on the characteristics of the fibers, the matrix, and their interface.

The influences on durability are divided into the effects of the external environment and the effects of the concrete's environment (applicable to the use of FRP for reinforcement).

The most important effects of the external environment are the thermal conditions, ultraviolet rays, and chemical attacks. The elastic modulus and strength of an FRP reinforcement decrease with high temperatures and a sustained load. Under the service temperature of concrete structures (from -20 to $+60{ }^{\circ} \mathrm{C}$ ), the reduction of the modulus of elasticity is negligible for CFRP; however, a slight reduction occurs for AFRP and GFRP. After exposure to ultraviolet rays, an AFRP reinforcement shows a $13 \%$ reduction in tensile strength, while GFRP shows an $8 \%$ reduction, and CFRP shows no reduction. The combined effect of ultraviolet and moisture exposure showed an even greater reduction in the material characteristics. Of the chemical effects, an acid attack is the most dangerous, but there is a lack of data in this field (fib Bulletin 40, 2007).

In comparison with a steel reinforcement, the effect of a concrete's alkalinity can harm an FRP reinforcement. The usual benefit of concrete in protecting a steel reinforcement could cause the deg- radation of an FRP reinforcement. Carbon fibers tend to show the best resistance to an alkali environment followed by aramid and glass fibers, the deterioration of which in an alkali environment is well known (Ceroni et al., 2006). The susceptibility of glass fibers to alkaline environments is primarily caused by the presence of silica in the glass fibers. Accelerated tests performed in aqueous solutions with a high $\mathrm{pH}$ at elevated temperatures are known to degrade the tensile strength of GFRP bars (Chen, 2007; Kim et al., 2006). Here, the role of the matrix as a protection agent is also important. Most researchers believe that vinyl-ester resins have superior resistance to the ingress of moisture compared with other commodity resins and therefore also provide better protection for glass fibers (ACI 440.1R-15, 2015).

A summary of results from Sweden for tensile strength reductions obtained for GFRP bars in alkaline solutions, concrete and water at $60{ }^{\circ} \mathrm{C}$ is shown in Fig. 1 (Dejke, 2001). It can be seen that after one year, the reduction in tensile strength starts to be stabilized in the case of an alkali environment. The concrete environment also represents a natural alkali environment for the reinforcement. It is interesting that the reduction in tensile strength was higher in this environment than in an alkaline solution. Also, the monitoring of bridge decks in Canada shows a smaller degree of degradation in GFRP rebars as assumed according to accelerated test methods. The results of a major study undertaken with regard to several structures across Canada indicate that no deterioration of the GFRP took place in any of these structures and that no chemical degradation processes occurred within the GFRP due to the concrete's alkalinity (Benmokrane and Mohamed, 2016; Gooranorimi and Nanni, 2017).

Another effect of a concrete environment on fibers is the presence of moisture. Carbon and glass fibers cannot absorb water, while water absorption in aramid fibers causes a reversible decrease in tensile strength, the modulus of elasticity, and fatigue strength (Ceroni et al., 2006).

To take into account a reduction in tensile strength due to environmental actions, the reduction factors are used in the existing guidelines.

\subsection{Creep rupture}

An FRP reinforcement subjected to a constant load over time can suddenly fail after a time period called the "endurance time". This phenomenon is known as "creep rupture". The endurance time of an FRP reinforcement decreases as the ratio of the sustained tensile stress to the short-term strength increases. The endurance time also decreases with the effects of high temperatures, exposure to ultraviolet radiation, a high degree of alkalinity, wet and dry cycles, and freeze-thaw cycles (ACI 440.1R-15, 2015). Carbon fibers have very good resistance to creep rupture. Aramid fibers are more susceptible

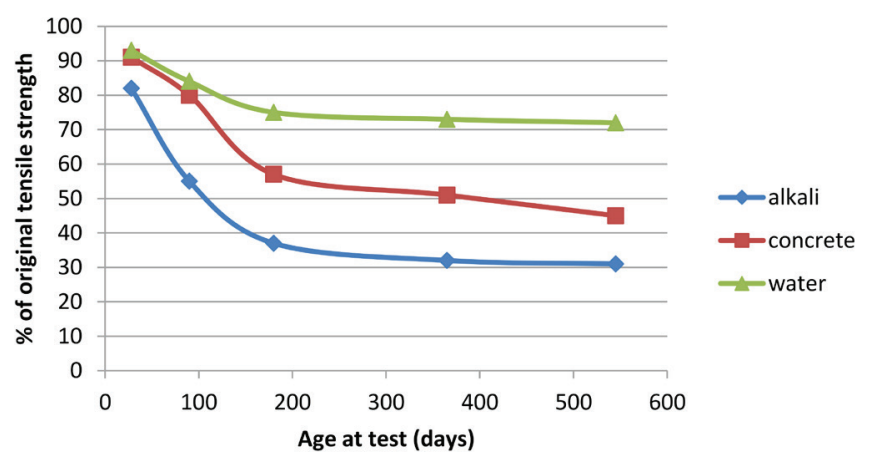

Fig. 1 Effect of environment on GFRP exposed to alkali, concrete and water (Dejke, 2001) 
to this phenomenon, while glass and basalt fibers are the most susceptible. Nevertheless, the susceptibility of resin is the biggest problem.

Some series of creep rupture tests were conducted on FRP reinforcements with different fibers (carbon, aramid, glass, basalt). Usually, the tests lasted for $100 \mathrm{~h}$, and the results were linearly extrapolated to $500,000 \mathrm{~h}$ (more than 50 years).

The results of the experimental program of Yamaguchi et al. (1997) showed the ratios of the level of stress at creep rupture to the initial strength to be 0.29 for GFRP, 0.47 for AFRP, and 0.93 for CFRP. In another extensive investigation (Ando et al. 1997), the percentage of stress at creep rupture versus the initial strength after 50 years was found to be 0.79 for CFRP and 0.66 for AFRP. Seki et al. (1997) reported a ratio of 0.55 for GFRP. A 50-year ultimate creep rupture strength coefficient of 0.18 was found by Banibayat and Patnaik (2015) to be suitable for BFRP reinforcement ( $f i b$ Bulletin 40, 2007).

There are two possibilities for avoiding creep rupture, i.e., adjust the material resistance of the FRP reinforcement or limit the stress level in the FRP reinforcement under sustained stresses.

\subsection{Fatigue}

The fatigue stress limit is the stress level below which a material can be stressed cyclically for an infinite number of times without failure. Glass fibers individually are not prone to fatigue failure. A GFRP reinforcement may lose about $10 \%$ of its initial static strength per decade of a logarithmic lifetime in the presence of cyclic tensile loading. CFRP composites are the least vulnerable to fatigue failure. Their fatigue strength is 3-4 times higher than that of prestressed steel. At one million cycles, the fatigue strength is usually between 50 and 70 $\%$ of the initial static strength. For AFRP, the fatigue strength after 2 million cycles was reported to be about 54 and $73 \%$ of the initial static strength (Ceroni et al., 2006; fib Bulletin 40, 2007).

\section{REDUCTION OF MATERIAL PROPERTIES DUE TO LONG-TERM EFFECTS}

Consideration of the durability properties and environmental conditions are established by the reduction factors summarized in Tab. 1.

The limitations according to the sustained load and creep rupture phenomenon are summarized in Tab. 2 .

Tab. 1 Durability reduction factors (fib Bulletin 40, 2007)

\begin{tabular}{lccc}
\hline & CFRP & GFRP & AFRP \\
\hline ACI 440.1R-15 & $0.95 f_{\mathrm{fu}}$ & $0.75 f_{\mathrm{fu}}$ & $0.85 f_{\mathrm{fu}}$ \\
NS3473 & $1.00 f_{\mathrm{fu}}$ & $0.50 f_{\mathrm{fu}}$ & $0.90 f_{\mathrm{fu}}$ \\
CSA-S806-02 CHBDC-2006 & $0.75 f_{\mathrm{fu}}$ & $0.50 f_{\mathrm{fu}}$ & $0.60 f_{\mathrm{fu}}$ \\
\hline
\end{tabular}

Tab. 2 Long-term stress limitation factors

\begin{tabular}{lcccc}
\hline & CFRP & GFRP & AFRP & BFRP \\
\hline ACI 440.1R-15 & $0.55 f_{\text {fu }}$ & $0.20 f_{\text {fu }}$ & $0.30 f_{\text {fu }}$ & - \\
Yamaguchi et al. (1997) & $0.93 f_{\mathrm{fu}}$ & $0.29 f_{\mathrm{fu}}$ & $0.47 f_{\mathrm{fu}}$ & - \\
$\begin{array}{l}\text { Ando et al. 1997 } \\
\text { Seki et al. (1997) }\end{array}$ & $0.79 f_{\mathrm{fu}}$ & - & $0.66 f_{\mathrm{fu}}$ & - \\
$\begin{array}{l}\text { Banibayat and Patnaik } \\
\text { (2015) }\end{array}$ & - & $0.55 f_{\mathrm{fu}}$ & - & - \\
\hline
\end{tabular}

\section{EXPERIMENTAL STUDIES}

An extensive experimental program conducted at the University of Girona, Spain, was aimed at investigating the long-term behavior of concrete beams reinforced with fiber-reinforced polymers. Two series of simply supported beams differing in concrete strength were tested over a period of 250 and 700 days ( $\approx 2$ years). The effects of the concrete strength, reinforcement ratio, and level of the sustained load were investigated. The beams were tested up to failure, and the flexural behavior of the unloaded beams with the beams under a sustained load was compared. The beams were subjected to two concentrated loads on a third of the span. The sustained loads were designed to induce instantaneous concrete compressive stresses equal to $0.3 f_{\mathrm{c}}$ and $0.45 f_{\mathrm{c}}$ (levels 1 and 2). During the testing, all the beams failed due to the concrete crushing. The greater values of the load capacity were observed for the beams that were subjected to a sustained load at levels 1 and 2, i.e., about $10 \%$ greater. After failure, small parts of the GFRP bars were extracted from the constant moment bending zone for investigation of their residual tensile properties; it was determined that the strength of the GFRP bars under a sustained load decreased by about $5 \%$ and that the modulus of elasticity was not affected (Mi-às et al., 2015).

When comparing the deflections, the time-dependent deflection increased by 1.2 to 2.0 times for 10 and 250 days of loading. This increase, as a multiplier of an initial deflection, is lower than that observed for beams with a steel reinforcement (Mi-às, 2013).

\section{EXPERIENCE ON ACTUAL STRUCTURES}

ISIS Canada launched a study to obtain field data with respect to the durability of GFRP in concrete. Drilled concrete cores were removed from five structures which were five to eight years old. The GFRP bars were separated from these cores and analyzed for their physical and chemical composition. A direct comparison was carried out with control specimens of the GFRP bars preserved under controlled laboratory conditions. The results found that there was no degradation of the GFRP bars. These results were used to improve the Canadian Bridge Design Code to allow the use of GFRP both as a primary reinforcement and for prestressing tendons in concrete elements. An important provision limited the stress level to $25 \%$ of the ultimate tensile strength for serviceability limit states (Kemp and Blowes, 2011).

Another example of the use of carbon and glass FRP in bridge engineering is from Missouri, USA, where a deteriorated bridge deck was replaced with FRP precast concrete panels. The performance of this bridge deck was studied for a four-year period. The bridge deck consists of nine FRP-reinforced precast concrete panels that are 864 $\mathrm{mm}$ wide, $7315 \mathrm{~mm}$ long, and $305 \mathrm{~mm}$ deep. The longitudinal reinforcement consists of GFRP bars on the top and CFRP bars on the bottom surface. The stirrups are made of GFRP. The bridge deck was monitored during load-testing with standard trucks. The measured deflections after four years of the deck's use were consistent with those at the beginning of the use. No significant loss of stiffness was observed (Deza and Nanni, 2005).

A special application of FRP in bridge engineering was a truss bridge made entirely of FRP, built in Shizuoka, Japan. The bridge has a span of $8.0 \mathrm{~m}$ and a superstructure weight of 3.8 tons. A pultruded GFRP hollow square pipe and U-section-shaped beams were used for the truss members. After nine years of exposure, the loading response of the FRP truss bridge exhibited almost the same behavior as just after its completion; thus, it has been confirmed that there was no deterioration in its structural performance. The results prove that FRP materials have good durability and functionality during long-term field exposure as structural material for bridges (Sasaki and Nishizaki, 2010). 


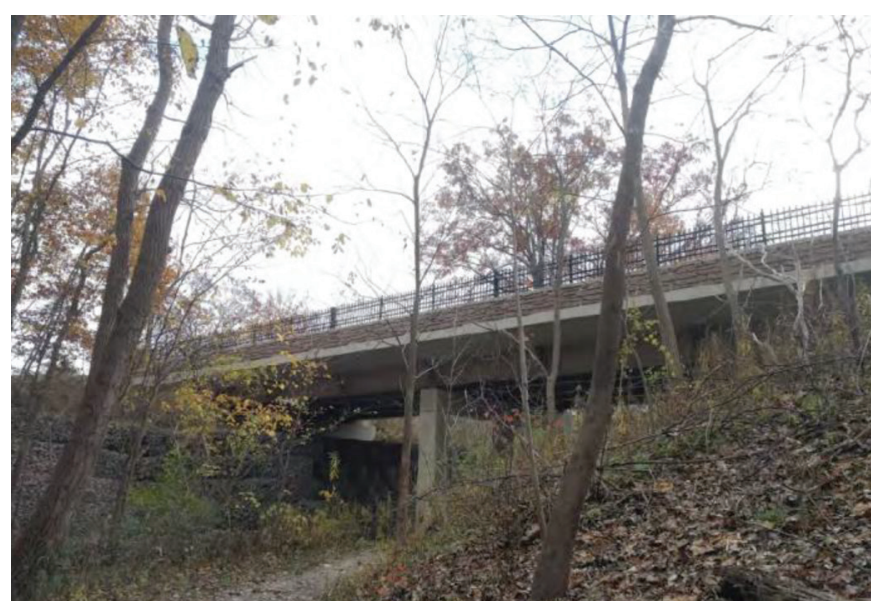

Fig. 2 Cuyahoga County Bridge (Miles Road Bridge No. 178) - deck entirely reinforced with GFRP rebars (Benzecry et al., 2019)

The Cuyahoga County Bridge in Ohio was built in 2002, and it has the first deck on a multi-span vehicular bridge to be entirely reinforced with GFRP rebars (Figure 2) (Benzecry et al., 2019).

\section{EXPERIMENTAL VERIFICATION}

Based on the need for actual experience over time to determine the true long-term degradation of FRP materials, an extensive experimental verification was prepared at the Slovak University of Tech- nology in Bratislava. The first part has already been realized. Six simply-supported concrete beams with a height of $74 \mathrm{~mm}$ on average and a width of $150 \mathrm{~mm}$, reinforced with two GFRP bars $\left(f_{\mathrm{fu}}=1000 \mathrm{MPa}\right)$ with a diameter of $8 \mathrm{~mm}$, were tested under a four-point bending test; the results were compared with the numerical calculations to verify the behavior of these members and to prepare an extensive number of specimens for long-term testing. The results of the first part of experimental study are summarized in Table 3 .

There is very good agreement between the calculated and measured values. According to this degree of compliance, the specimens could be studied in more detail. It is very complicated to measure the value of stress in a GFRP reinforcement, but it is necessary to know this value for designing a long-term load. According to the calculations, the stress in a GFRP reinforcement at the moment of failure was about $650 \mathrm{MPa}$. All the beams failed due to concrete crushing, and the average value of the strain at the compression surface of the concrete was $3.8 \%$. This value was then used in the adapted calculations.

If the reduction factors from Tables 1 and 2 are used, the maximal allowed stress in a GFRP reinforcement for long-term loading is about 100 150 MPa, which means the tested beams would fail when loaded at a level of one fourth of their resistance. This fact could be confirmed or refuted during the following part of the experimental verification. Almost 100 beams will be tested after one, two, five and ten years of long-term loading on the levels of 25, 50 and $75 \%$ of their resistance. Some specimens will be placed in laboratory conditions and some in an exterior environment (effect of different levels of humidity) and some in an aggressive environment (wastewater treatment plant). During testing, the increase in deflection will be measured. According to the deflection and maximal resistance of the

Tab. 3 Results from the numerical calculation and experimental verification of short-term tests

\begin{tabular}{|c|c|c|c|c|c|c|}
\hline & & $\begin{array}{l}\text { Maximal resistance } \\
(\mathrm{kN})\end{array}$ & $\begin{array}{l}\text { Deflection in the } \\
\text { middle }(\mathrm{mm})\end{array}$ & $\begin{array}{l}\text { Ultimate strain of } \\
\text { concrete }(\%) \text { ) }\end{array}$ & $\begin{array}{l}\text { Height of the cross } \\
\text { section }(\mathrm{mm})\end{array}$ & $\begin{array}{l}\text { Thickness of the } \\
\text { cover layer (mm) }\end{array}$ \\
\hline \multirow{6}{*}{ 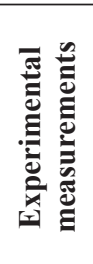 } & N1 & 10 & 44 & 3.6 & 76 & 19 \\
\hline & N2 & 8.57 & 50 & 3.8 & 73 & 19 \\
\hline & N3 & 8.46 & 41 & - & 73 & 20 \\
\hline & N4 & 9.5 & 41 & 3.8 & 75 & 20 \\
\hline & N5 & 8.98 & 35 & 3.9 & 73 & 19 \\
\hline & N6 & 9.39 & 39.5 & - & 74 & 19 \\
\hline \multicolumn{2}{|c|}{ average } & 9.15 & 41.9 & 3.8 & 74 & 20 \\
\hline \multicolumn{2}{|c|}{ Calculated values } & 9.2 & 37.9 & - & - & - \\
\hline
\end{tabular}
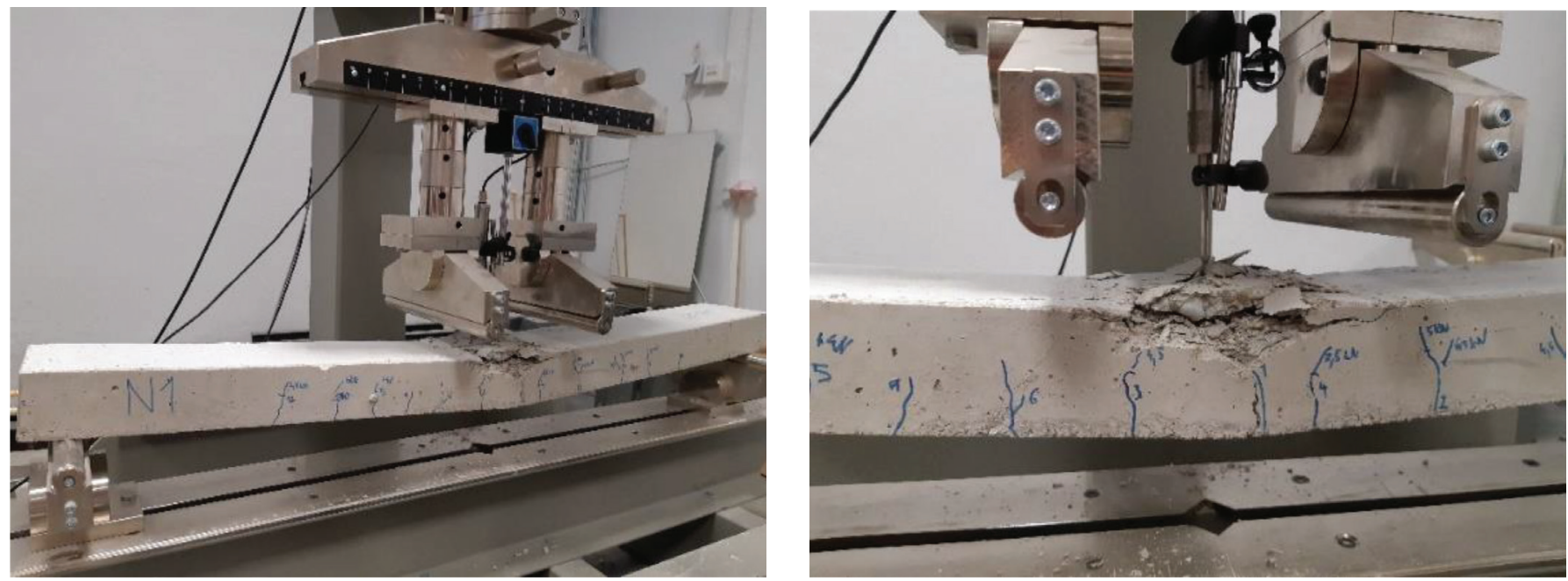

Fig. 3 Beam after failure 
beams, the predicted stress in the reinforcement will be calculated. The increase in deflection during long-term loading will be measured by deformeters. During the testing, linear variable differential transformers (LVDTs) will be used.

\section{CONCLUSIONS}

According to the reduction factors summarized in Tabs. 1 and 2, it can be concluded that the existing design guidelines for FRP reinforcements strictly limit their usability according to durability effects and the creep rupture phenomenon.

The results from the calculated example show a reduction of the resistance of $80 \%$ for durability and additional long-term properties of a GFRP reinforcement.

Nevertheless, it cannot be stated that FRP composites will not reliably satisfy their function in a structure and that structures with an FRP reinforcement will fail before reaching their service life because the values of residual stresses have only been extrapolated from accelerated short-term tests, and because we need actual experience over time to judge the true long-term degradation of these materials.

Field investigations have shown that the concrete environment is, however, not as aggressive as alkaline solutions and that alkali resistance can be significantly improved by the selection of appropriately treated glass fibers, suitable resins, and better production techniques.

The experience observed from actual structures after sustained loading shows a similar response as that just at the beginning of their use. This means that the very strict assumptions for the reduction of tensile properties do not seem to be correct.

\section{Acknowledgments}

This work was supported by the Slovak Research and Development Agency under the Contract No. APVV-17-0204, by the Scientific Grant Agency VEGA under the Contract No. VEGA 1/0522/20 and the University Science Park (USP) of the Slovak University of Technology in Bratislava (ITMS: 26240220084). 


\section{REFERENCES}

ACI 440.1R-15, American Concrete Institute (2015), Guide for the Design and Construction of Structural Concrete Reinforced with FRP Bars.

Banibayat, P. and Patnaik, A. (2015) Creep rupture performance of basalt fiber-reinforced polymer bars, Journal of Aerospace Engineering 28(3), 1-6.

Benmokrane, B. - Elgabbas, F. - Ahmed, E. A. - Cousin, P. (2015) Characterization and comparative durability study of glass/vinylester, basalt/vinylester, and basalt/epoxy FRP bars", Journal of Composites for Construction, vol. 19, no. 6 .

Benmokrane, B. - Mohamed, H. (2016) Use of Fiber-Reinforced Polymer (FRP) Rebars for Building Durable Concrete Infrastructure, The Sixth International Conference on Structural Engineering, Mechanics and Computation (SEMC 2016), Cape Town, South Africa, 2016.

Benzecry, V. - Brown, J. - Al-Khafaji, A. - Haluya, R. - Koch, R. - Nagarajan, M. - Bakis, C. E. - Myers, J. J. - Nanni, A. (2019) Durability of GFRP Bars Extracted from Bridges with 15 to 20 Years of Service Life, Technical Report, University of Miami, 2019.

Ceroni, F. - Cosenza, E. - Gaetano, M. - Pecce, M. (2006) Durability issues of FRP rebars in reinforced concrete members, Cement and Concrete Composites 28 (10), 857-868.

Chen, Y. - Davalos, J. F. - Ray, I. - Kim, H. Y. (2007) Accelerated aging tests for evaluation of durability performance of FRP reinforcing bars reinforcing bars for concrete structures, Composite Structures, 78(1), 101-111.

Dejke, V. (2001) Durability of FRP Reinforcement in Concrete, $\mathrm{PhD}$. Thesis at Dept of Building Materials, Chalmer University of Technology, Goteborg, Sweden.
Deza, U. - Nanni, A. (2005) Performance Evaluation of a Short-Span Bridge Built with FRP Reinforced Concrete Panels, ACI Special Publication, Vol. 230, 1191-1208, 2005.

fib Bulletin 40 (2007) FRP reinforcement in RC structures. Fédération Internationale du Béton (fib), Lausanne, Switzerland.

Gooranorimi, O. and Nanni, A. (2017) GFRP reinforcement in concrete after 15 years of service, Journal of Composites for Construction 21(5).

Kemp, M. - Blowes, D. (2011) Concrete Reinforcement and Glass Fiber Reinforced Polymer, Queensland Roads Edition, no. 11, $40-48$.

Kim, H. Y. - Park, Y. H. - You, Y. J. - Moon, C. K. (2006) Durability of GFRP Composite Exposed to Various Environmental Conditions, KSCE Journal of Civil Engineering 10(4), 291-295.

Mi-às, C. - Guadagnini, M. - Torres, L. - Barris, C. - Fergani H. (2015) Strength of GFRP RC beams after sustained loading, Proceedings of Joint Conference of the 12th International Symposium on Fiber Reinforced Polymers for Reinforced Concrete Structures, FRPRCS 2015 and the 5th Asia-Pacific Conference on Fiber Reinforced Polymers in Structures, APFIS, 2015.

Mi-às, C. - Torres, L. - Turon, A. - Barris, C. (2013) Experimental study of immediate and time-dependent deflections of GFRP reinforced concrete beams, Composite Structures 96(0), 279-285.

Sasaki, I. - Nishizaki, I. (2010) Load-bearing properties of an FRP bridge after nine years of exposure, Proceedings of CICE 2010 - The 5th International Conference on FRP Composites in Civil Engineering, Beijing, China, 2010. 